\title{
Melastomataceae na Área de Proteção Ambiental Tambaba, Litoral Sul da Paraíba, Brasil
}

\author{
Melastomataceae in the Tambaba Environmental Protection Area, \\ southern coastal zone of Paraíba, Brazil
}

Cínthia Menezes Lima Ramos Araújo ${ }^{1,2}$ \& Rita Baltazar de Lima ${ }^{1}$

\begin{abstract}
Resumo
Este trabalho apresenta um levantamento florístico da família Melastomataceae no Litoral Sul do estado da Paraíba. A área de estudo abrangeu os municípios do Conde, Pitimbu e Alhandra, localizados na microrregião do Litoral Sul Paraibano, incluindo os limites da APA Tambaba, uma unidade de conservação de uso sustentável, no Bioma Mata Atlântica. A família está representada na área por seis gêneros e dez espécies: Clidemia biserrata DC., C. hirta (L.) D. Don, Comolia villosa (Aubl.) Triana, Henriettea sp., Miconia albicans (Sw.) Triana, M. amoena Triana, M. ciliata (Rich.) DC., M. prasina (Sw.) DC., Nepsera aquatica Naudin e Pterolepis glomerata (Rottb.) Miq. São apresentadas chaves de identificação, descrições, ilustrações e comentários para as espécies.

Palavras-chave: Mata Atlântica, levantamento florístico, sistemática.
\end{abstract}

\begin{abstract}
This paper presents a floristic survey of the family Melastomataceae in the southern coastal zone of the state of Paraíba. The study area comprises the municipalities of Conde, Pitimbu and Alhandra, located in the South Coast micro-region of Paraíba, including the limits of the APA Tambaba, a sustainable use conservation area within the Atlantic Forest Biome. The family is represented in the area by six genera and ten species: Clidemia biserrata DC., C. hirta (L.) D. Don, Comolia villosa (Aubl.) Triana, Henriettea sp. Miconia albicans (Sw.) Triana, M. amoena Triana, M. ciliata (Rich.) DC., M. prasina (Sw.) DC., Nepsera aquatica Naudin and Pterolepis glomerata (Rottb.) Miq. This paper provides identification keys to the species and descriptions, illustrations, and comments for each species.
\end{abstract}

Key words: Atlantic Forest, floristic survey, systematic.

\section{Introdução}

A família Melastomataceae reúne indivíduos herbáceos, arbustivos, arbóreos ou lianas, com distribuição nos trópicos, em florestas montanas e de terras baixas, savanas e áreas degradadas (Clausing \& Renner 2001), incluindo cerca de 150 gêneros e 4.500 espécies (Renner et al. 2010). Na Floresta Atlântica, a família tem sido considerada um grupo importante pela densidade de suas populações (Baumgratz et al. 2006).

No Brasil, a família ocorre desde a Amazônia ao Rio Grande do Sul, tendo sido encontrada em praticamente todas as formações vegetais, estando representada por 1.321 espécies, distribuídas em 67 gêneros, correspondendo a sexta maior família de Angiospermas do país (Romero \& Martins 2002; Baumgratz et al. 2006, 2012).
Melastomataceae foi estabelecida por Jussieu (1789) e, posteriormente, recebeu a contribuição de outros autores clássicos, como De Candolle (1828), Triana (1871), Cogniaux (1891), Krasser (1893) e Vliet et al. (1981). Renner (1993) propôs, com base em análise filogenética morfológica, que a família fosse classificada em duas subfamílias e nove tribos: Kibessioideae com uma tribo e Melastomatoideae com oito. Mais recentemente, Clausing \& Renner (2001), a partir de filogenética molecular, demonstram que Melastomataceae é grupo irmão de Memecylaceae, podendo ser consideradas tanto como uma única família ou como famílias distintas.

Os trabalhos mais recentes têm sido realizados principalmente nas Regiões Sul e Sudeste do Brasil (Romero \& Martins 2002; Goldenberg 2004;

\footnotetext{
${ }^{1}$ Universidade Federal da Paraíba, Centro de Ciências Exatas e da Natureza, Depto. Sistemática e Ecologia, Lab. Taxonomia, Cidade Universitária, 58051-970, João Pessoa, PB, Brasil.

${ }^{2}$ Autor para correspondência: cinthia.limaramos@gmail.com
} 
Baumgratz \& Souza 2005; Goldenberg et al. 2005, 2012; Baumgratz \& Chiavegatto 2006; Baumgratz et al. 2006, 2007; Camargo \& Goldenberg 2007; Kinoshita et al. 2007; Barberena et al. 2008, 2010; Silva \& Romero 2008; Camargo et al. 2009; Meyer et al. 2010; Renner \& Goldenberg 2011).

$\mathrm{Na}$ Região Nordeste, as espécies de Melastomataceae têm sido citadas em levantamentos florístico gerais (Oliveira-Filho \& Carvalho 1993; Rodal \& Nascimento 2002; Barbosa et al. 2004; Sobrinho \& Queiroz 2005; Oliveira et al. 2006; Pereira \& Alves 2006; Pessoa et al. 2009; Souza et al. 2009; Barbosa et al. 2011), estando os trabalhos voltados especificamente para família concentrados no estado da Bahia (Martins 2000; Santos 2005, 2009; Santos \& Silva 2005; Santos et al. 2008; Amorim et al. 2009; Jardim 2010; Baumgratz et al. 2011; Freitas et al. 2012). Para os outros estados há poucas publicações (Araújo 2001; Lima et al. 2007; Conceição et al. 2010) e, recentemente, o gênero Miconia foi estudado para o Nordeste Oriental (Chagas 2012).

$\mathrm{Na}$ Paraíba, alguns estudos com Melastomataceae estão em andamento, no entanto, sua riqueza ainda é pouco conhecida, devido à quase inexistência de estudos exclusivos sobre a família. Levando em conta a escassez de informações sobre as Melastomataceae neste estado, este trabalho teve como objetivo principal, realizar um estudo taxonômico sobre as espécies que ocorrem na Mata Atlântica do Litoral Sul da Paraíba.

\section{Material e Métodos}

Área de estudo

O estudo foi realizado nos municípios do Conde, Pitimbu e Alhandra, localizados na mesorregião da Mata Paraibana, microrregião do Litoral Sul Paraibano, abrangendo os limites da APA Tambaba (Fig. 1), uma Unidade de Conservação de uso sustentável, inserida no Bioma Mata Atlântica, abrangendo uma área de 11.320 hectares (SUDEMA 2012). A sua cobertura vegetal está estabelecida sobre a unidade geomorfológica dos Tabuleiros Costeiros, sendo constituída por formações florestais, denominadas Matas de Tabuleiro e manchas de Cerrado, que ocorrem em locais onde o solo é mais arenoso e a vegetação é arbustiva-arbórea, sendo localmente chamadas de Tabuleiros (Barbosa \& Thomas 2002).

Atividades de campo e de laboratório

Visitas mensais à APA Tambaba foram realizadas, entre os meses de julho de 2008 e julho de 2010, para observações de campo e coleta de material em toda a área estudada. Espécimes férteis foram coletados e fotografados in loco, sendo posteriormente analisados em laboratório e incorporados à coleção do Herbário JPB.

As identificações foram feitas com o auxílio da literatura de referência (Goldenberg et al. 2005; Seco 2006), por comparação com material das coleções dos Herbários IPA, JPB e UFP, além de consulta ao especialista Dr. Renato Goldenberg. Todas as espécies foram descritas e ilustradas com auxílio

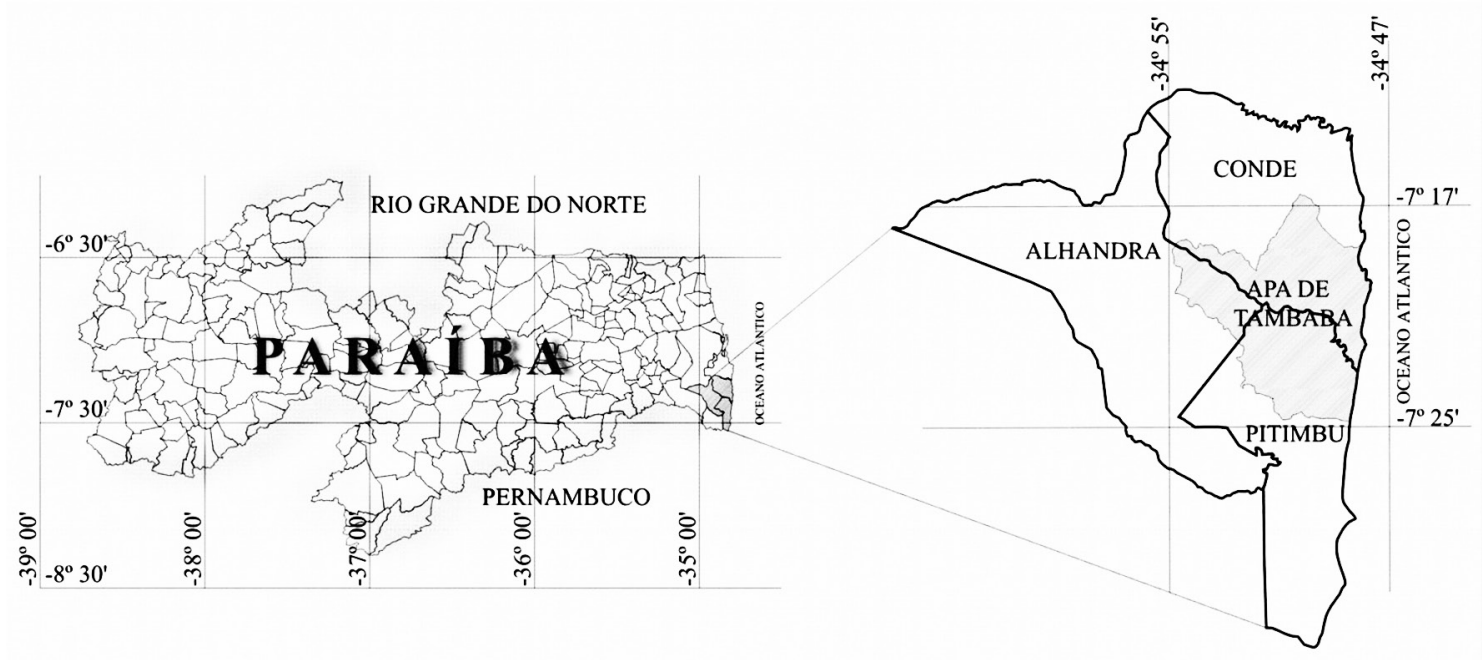

Figura 1 - Localização da APA Tambaba (Fonte: Pedrosa 2006). Figure 1 - Localization of APA Tambaba (Font: Pedrosa 2006). 
de câmara-clara. Apenas Henriettea sp. não recebeu uma descrição mais completa, devido à carência de material fértil. As chaves analíticas e as descrições foram elaboradas com base no material coletado e quando necessário, complementadas com o material adicional. Para a distribuição geográfica das espécies foram utilizadas as informações contidas em exsicatas e no sítio da Lista de Espécies da Flora do Brasil (Baumgratz et al. 2012).

\section{Resultados e Discussão}

Na APA Tambaba a família Melastomataceae está representada por seis gêneros e dez espécies, ocorrendo em Mata de Tabuleiro e Tabuleiro. O gênero mais bem representado é Miconia Ruiz \& Pavon com quatro espécies, seguido de Clidemia D.Don, com duas espécies e Comolia DC., Henriettea DC., Nepsera Naudin e Pterolepis (DC.) Miq. com uma espécie cada.

A maioria das espécies de Melastomataceae registradas para a área é de ampla distribuição. Miconia amoena Triana foi a única espécie com ocorrência restrita na Mata Atlântica e Comolia villosa (Aubl.) Triana, assim como N. aquatica (Aubl.) Naudin até o momento são restritas às Regiões Norte e Nordeste do país (Baumgratz 2012a, 2012c; Goldenberg 2012).

O estudo comparativo com outros levantamentos florísticos realizados na Região Nordeste, mostrou cinco espécies em comum com os trabalhos de Araújo (2001) e Santos \& Silva (2005), quatro espécies em comum com Lima et al. (2007) e Jardim (2010) e duas espécies também encontradas por Conceição et al. (2010). Entretanto, as únicas espécies não registradas nos trabalhos analisados foram C. villosa, M. amoena e $N$. aquatica.
Melastomataceae na APA Tambaba

Ervas, subarbustos ou arbustos com indumento glanduloso ou não. Folhas simples, pecioladas, oposto-cruzadas, ovaladas, elípticas ou oblongas, nervação acródroma basal ou suprabasal, com 3 a 5 nervuras. Flores diclamídeas, 4-meras ou 5-meras, raro 6-meras, actinomorfas, andróginas, isoladas ou em inflorescências axilares ou terminais, dicasiais, glomerulares ou escorpioides. Sépalas, total ou parcialmente fundidas, com dois verticilos ou não. Corola dialipétala; pétalas alvas, rosadas ou lilases; hipanto oblongo ou globoso; androceu diplostêmone, anteras com deiscência poricida; ovário súpero ou ínfero, 2-5-carpelar, 2-5-locular, muitos óvulos por lóculo, placentação axilar. Fruto baga ou cápsula loculicida, jovem verde ou creme, madura castanha, creme, atroviolácea ou verde-jade.

\section{Clidemia D. Don}

Arbustos com indumento variado e ramos cilíndricos. Folhas ovais, face adaxial bulada, abaxial foveolada, concolores. Inflorescências axilares, em cimeiras dicasiais, tirsoides. Brácteas e bractéolas persistentes ou decíduas. Flores 5-meras, raro 6-meras; hipanto globoso, coberto por tricomas ramificados ou filiformes, glandular ou não; cálice duplo; corola alva, pétalas subarredondadas, oblongas ou obovadas, glabras; estames alvos, isodínamos, isomórficos, filetes creme, glabros, anteras alvas, subuladas, uniporadas, conectivo não prolongado; ovário 5(-6)-carpelar, 5(-6)-locular, muitos óvulos por lóculo, placentação axilar; estilete alvo, glabro. Bagas jovens verdes, maduras atrovioláceas.

\section{Chave para as espécies de Melastomataceae da APA Tambaba}

1. Arbustos maiores que $1 \mathrm{~m}$ alt.

2. Folhas ovais.

3. Ramos com tricomas não hirsutos, glandulosos, estrelados estipitados e estrelados sésseis; hipanto globoso; pétalas subarredondadas a levemente oblonga ...... 1.1 Clidemia biserrata

3'. Ramos com tricomas hirsutos, não glandulosos, não ramificados, não estipitados; hipanto urceolado; pétalas oblongas a levemente obovadas 1.2 Clidemia hirta

2'. Folhas elípticas, oblongas ou obovadas.

4. Ramos e folhas com indumento estrigoso 3.1 Henriettea sp.

4'. Ramos e folhas com indumento estrelado, filiforme ou lanoso.

5. Folhas 5-nervadas; inflorescências escorpioides.

6. Ramos, face abaxial das folhas e inflorescências densamente revestidos por indumento lanoso; hipanto densamente lanoso; corola e androceu alvos 
6'. Ramos, face abaxial das folhas e inflorescências podendo apresentar tricomas filiformes; hipanto glabro; corola e androceu róseos ou lilases

5'. Folhas 3-nervadas; inflorescências glomerulares.

7. Ramos, face abaxial das folhas e inflorescências densamente revestidos por indumento lanoso; folhas com as nervuras basais; hipanto densamente lanoso 4.2 M. amoena

7'. Ramos, face abaxial das folhas e inflorescências podendo apresentar tricomas estrelados sésseis; folhas com um par de nervuras supra-basais; hipanto glabro 4.4 M. prasina

1'. Ervas ou subarbustos menores que $0,8 \mathrm{~m}$ alt.

8. Lâmina foliar pubescente nas duas faces; flores com corola rosa a lilás; cálice piloso; pétalas com ápice arredondado.

9. Hipanto com tricomas ramificados, anteras amarelas com ápice lilás 6.1 Pterolepis glomerata

9' Hipanto com tricomas não ramificados, anteras completamente lilases

2.1 Comolia villosa

8'. Lâmina foliar glabra nas duas faces; flores com corola alva; cálice glabro, pétalas com ápice agudo 5.1 Nepsera aquatica

1.1. Clidemia biserrata DC., Prodr. 3: 158. 1828.

Fig. 2a-d

Arbustos, 1,3-1,5 m alt.; ramos jovens recobertos por tricomas glanduloso-estipitados, estrelado-estipitados e estrelados sésseis. Folha com pecíolo $0,5-2,5 \mathrm{~cm}$ compr., deflexa; lâmina 4-11 × 1,8-7,2 cm, opaca, oval, base cordada, ápice acuminado a cuspidado, margem denteada, ciliada; face adaxial com tricomas filiformes não glandulosos, face abaxial com tricomas estrelados sésseis e estreladoestipitados; 5 nervuras basais. Inflorescências dicasiais axilares, 5,5-11 × 3-10 cm. Brácteas e bractéolas ca. $2 \mathrm{~mm}$ compr., filiformes, bractéolas persistentes. Flores 1-1,2 cm compr.; pedicelo $2-5 \mathrm{~mm}$ compr.; hipanto ca. $3 \times 4 \mathrm{~mm}$, globoso, com tricomas filiformes, glanduloso-estipitados, estrelados sésseis e estrelado-estipitados; tubo do cálice ca. $1 \mathrm{~mm}$ compr., lacínios externos ca. $2 \times 1,5 \mathrm{~mm}$ compr., deltoides, ápice aristado, lacínios internos 1-1,5 × 0,9-1,1 mm, deltoides, ápice agudo; pétalas 3,3-3,8 $\times 2,5-3 \mathrm{~mm}$, subarredondadas a ligeiramente oblongas, base truncada, ápice às vezes apiculado; estames isomórficos, filete 1,9-2,1 mm compr., anteras 2-2,2 mm compr.; ovário ca. 2,2 × 2 $\mathrm{mm}$, piloso no ápice, tricomas ca. $1 \mathrm{~mm}$ compr., glandulosos, estipitados; estilete 4-6 mm compr. Bagas 5-7 × 4-5 mm.

Material examinado: Pitimbu, APA Tambaba, Bacia do Mucatu, 25.IX.2009, fl. e fr., C.M.L.R. Araújo et al. 189 (JPB); Andreza II, 16.IV.2010, f1. e fr., C.M.L.R. Araújo et al. 206 (JPB); 19.III.2010, fl. e fr., C.M.L.R. Araújo et al. 203 (JPB); 16.IV.2010, fl. e fr., C.M.L.R. Araújo et al. 207 (JPB).
Clidemia biserrata pode ser facilmente reconhecida por suas folhas opacas e deflexas, indumento com tricomas glandulosos bastante variados e hipanto globoso. Suas inflorescências normalmente apresentam-se bastante laxas com flores 5-meras ou 6-meras.

No Brasil, a espécie é amplamente distribuída ocorrendo em todo o território (Michelangeli \& Reginato 2012). Na Paraíba, além dos municípios Alhandra, Conde e Pitimbu, a espécie foi encontrada em João Pessoa, Mamanguape e Rio Tinto.

$\mathrm{Na}$ área de estudo os indivíduos de $C$. biserrata foram encontrados às margens de cursos d'água e nas bordas dos fragmentos de Mata de Tabuleiro. Em locais abertos, C. biserrata foi encontrada onde havia sombra em algum momento do dia, mas sempre próxima a cursos d'água.

1.2. Clidemia hirta (L.) D. Don, Mem.Wern.Nat. Hist.Soc. 4 (2): 309. 1823.

Fig. 2e-f

Arbustos, 1,2-1,3 m alt.; ramos com tricomas hirsutos, não glandulosos, estrelado-estipitados e estrelados sésseis. Folha com pecíolo $0,8-3 \mathrm{~cm}$ compr., patente; lâmina 6-13 ×3,5-7,3 cm, lustrosa, oval, base cordada, ápice cuspidado a acuminado, margem denteada a crenada, ciliada; ambas as faces com tricomas hirtos, não glandulosos; 5 nervuras basais. Inflorescências dicasiais axilares, 2,6-3,6 $\times 3,5-4,5 \mathrm{~cm}$. Brácteas $2-3 \mathrm{~mm}$ compr., filiformes; bractéolas ca. $2 \mathrm{~mm}$ compr., similares às brácteas, persistentes. Flores 1-1,3 cm compr.; pedicelo ca. 5 mm compr.; hipanto ca. 3,5 × 3-3,5 mm, urceolado, com tricomas hirsutos, estrelados estipitados e estrelados sésseis; tubo do cálice ca. $1 \mathrm{~mm}$ compr., 


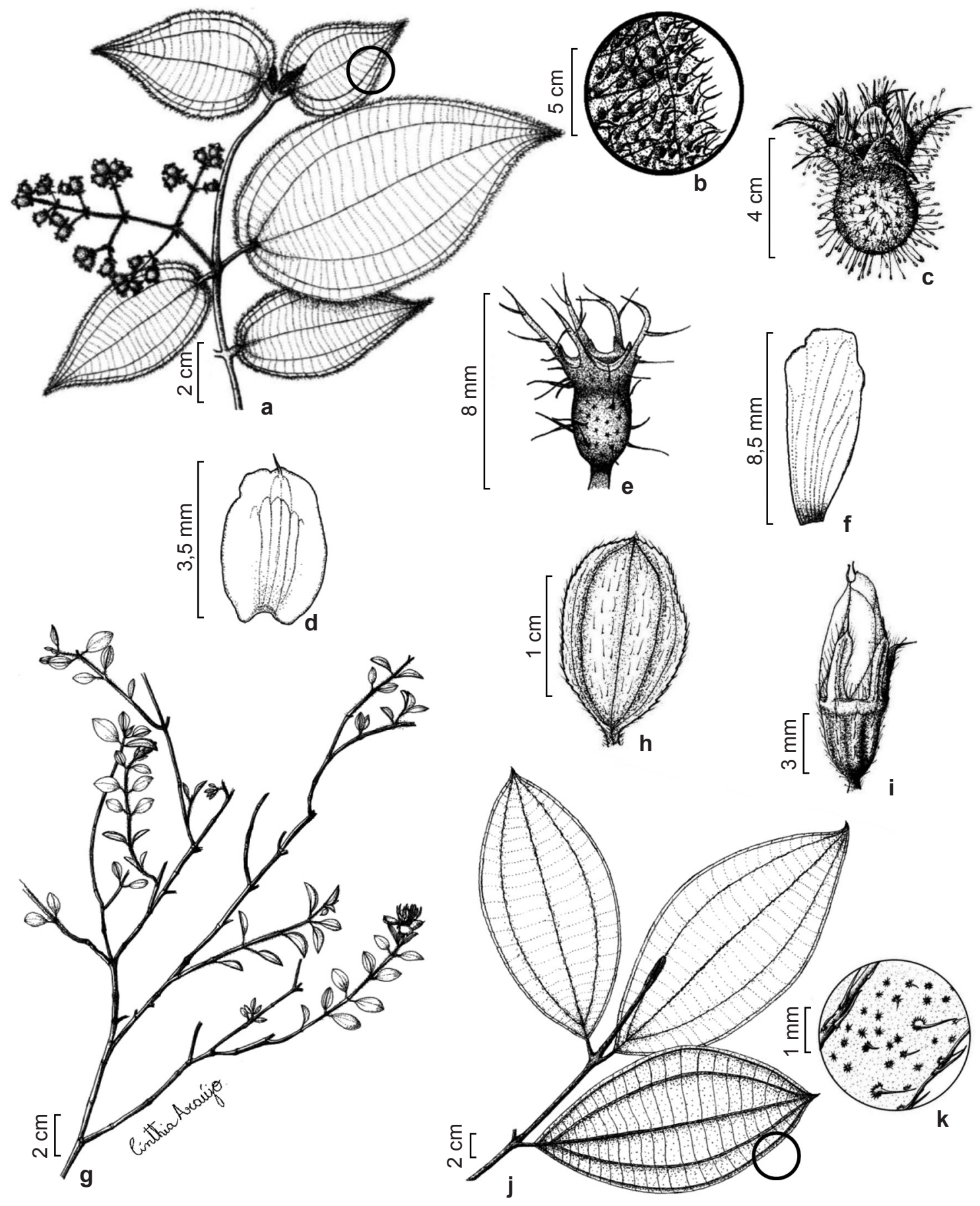

Figura 2 - a-d. Clidemia biserrata DC. - a. hábito; b. detalhe da folha, face adaxial; c. cálice; d. pétala. e-f. C. hirta (L.) D. Don - e. cálice; f. pétala. g-i. Comolia villosa (Aubl.) Triana - g. hábito; h. folha, face adaxial; i. botão floral. j-k. Henriettea sp. - j. hábito; k. detalhe da folha, face abaxial. (a-d Araújo 203; e-f Araújo 210; g-i Araújo 215; j-k Araújo 242).

Figure 2 - a-d. Clidemia biserrata DC - a. habit; b. leaf detail, adaxial face; c. calyx; d. petal. e-f. C. hirta (L.) D. Don - e. calyx; f. petal. g-i. Comolia villosa (Aubl.) Triana - g. habit; h. leaf, adaxial face; i. floral bud. j-k. Henriettea sp. - j. habit; k. leaf detail, abaxial face. (a-d Araújo 203; e-f Araújo 210; g-i Araújo 215; j-k Araújo 242). 
lacínios externos ca. 2,5 mm compr., filiformes, ápice aristado, lacínios internos ca. $1 \times 0,5 \mathrm{~mm}$, deltoides, ápice agudo; pétalas 7,5-8,5 ×4-4,5 mm, oblongas a levemente obovadas, glabras, base truncada, ápice obtuso; estames isomórficos, filete 3,1-3,5 mm compr., anteras 5,1-5,5 mm compr., calcar ca. 0,5 mm compr.; ovário ca. $4 \times 2,1 \mathrm{~mm}$, oval a oblongo, glabro; estilete ca. $9 \mathrm{~mm}$ compr. Bagas ca. $9 \times 6 \mathrm{~mm}$.

Material examinado: Conde, APA Tambaba, Mata da Chica, 21.V.2010, fl. e fr., C.M.L.R. Araújo et al. 210 (JPB); 28.V.2010, fl. e fr., C.M.L.R. Araújo et al. 217 (JPB).

Clidemia hirta pode ser facilmente reconhecida pelas folhas lustrosas e patentes, pelos tricomas hirsutos e hipanto urceolado. Além disso, as suas inflorescências são menores, congestas e as flores são maiores do que as observadas em C. biserrata.

No Brasil, a espécie é amplamente distribuída ocorrendo em todas as regiões do país (Michelangeli \& Reginato 2012). Na Paraíba, além dos municípios Alhandra, Conde e Pitimbu, a espécie foi encontrada em Areia, Bananeiras, João Pessoa, Mamanguape, Rio Tinto, Santa Rita, Sapé e Serraria.

Assim como C. biserrata, C. hirta foi observada principalmente nas bordas dos fragmentos de Mata de Tabuleiro. As observações de campo mostraram que os espécimes de $C$. hirta apresentavam sinais de herbivoria, provavelmente ocasionada por formigas, uma vez que a presença constante desses insetos nas plantas foi percebida durante as pesquisas.

\section{Comolia DC.}

2.1. Comolia villosa (Aubl.) Triana, Trans. Linn. Soc. London 28: 37.1871 (1872). Fig. 2g-i

Subarbustos, 50-80 cm alt.; ramos jovens com indumento setoso, tricomas glandulares ou não. Folha com pecíolo 2-5 mm compr., patente; lâmina concolor, 1-3 × 0,6-2,2 cm, opaca, elíptica ou estreitamente obovada a subrotunda, base aguda, ápice agudo ou obtuso, margem serreada a crenada, ciliada; ambas as faces com indumento setoso, tricomas glandulares ou não; 3 nervuras basais, raramente 5. Inflorescências dicasiais, axilares ou terminais, 2-3 × 2,5-3 cm. Brácteas 7-8 × 2-3 mm, largamente obovadas; bractéolas 1-2 ×0,9-1,1 mm, oblongo-lanceoladas, persistentes. Flores 1-1,3 cm compr.; pedicelo 1-2 mm compr.; hipanto ca. $4 \mathrm{~mm}$ compr., oblongo, com tricomas filiformes, glandulares ou não; tubo do cálice $0,5-1 \mathrm{~mm}$ compr., lacínios 3-4 × 1-1,5 mm, oblongo-lanceolados, ápice obtuso; pétalas 10-13,4 × 4,8-5,5 mm, lilases, obovadas, glabras, base truncada, ápice arredondado a apiculado; estames sub-isomórficos, lilases; maiores com filete 2,8-4 mm compr., anteras 5,1-6 mm compr., subuladas, conectivo prolongado ca. $1 \mathrm{~mm}$ compr., apêndice ventral ca. 1 mm compr., bituberculado, cálcar ausente; menores com filete 2,1-3,2 mm compr., anteras 4,5-5,5 mm compr., subuladas, conectivo prolongado $0,5-1 \mathrm{~mm}$ compr., apêndice ventral ca. 0,5-0,6 mm compr., bituberculado, cálcar ausente; ovário 2-(3)-locular, livre, 2,5-3 mm compr., oblongo, glabro; estilete 6,2-7 mm compr. Cápsula loculicida 4-5 × 3-4 mm, jovem verde, madura castanha.

Material examinado: Conde, APA Tambaba, Vale do Bucatu, 6.XI.2009, fl., C.M.L.R. Araújo et al. 192 (JPB); Mata da Chica, 28.V.2010, fl. e fr., C.M.L.R. Araújo et al. 215 (JPB); 21.V.2010, fl., C.M.L.R. Araújo et al. 211 (JPB); 28.V.2010, fl. e fr., C.M.L.R. Araújo et al. 216 (JPB); 9.VII.2010, fl., C.M.L.R. Araújo, G.A. GomesCosta 218 (JPB).

Comolia villosa apresentou grande variação no tamanho e forma das folhas, apresentando lâminas foliares bastante estreitas até lâminas quase subrotundas. $\mathrm{O}$ indumento também variou em alguns indivíduos, quanto à presença ou não de glândulas. Nesta espécie, os indivíduos quando intensamente expostos ao sol, apresentam as partes mais jovens dos ramos, folhas e lacínios do cálice avermelhadas.

No Brasil, a espécie ocorre nas Regiões Norte e Nordeste (Baumgratz 2012a). Na Paraíba, além dos municípios Alhandra, Conde e Pitimbu, foi encontrada em João Pessoa e Mamanguape. Este é o primeiro registro da espécie para o estado.

$\mathrm{Na}$ área de estudo $C$. villosa ocorre predominantemente em locais com solo arenoso, constantemente ou periodicamente alagado. As flores dos espécimes estudados foram frequentemente encontradas, em campo, com evidências de herbivoria, sendo as anteras as estruturas florais mais atacadas, uma vez que eram predadas antes mesmo da antese.

\section{Henriettea DC.}

3.1 Henriettea sp.

Fig. $2 \mathrm{j}-\mathrm{k}$

Arbustos ca. $2 \mathrm{~m}$ alt., ramos cilíndricos com indumento estrigoso. Folha com pecíolo $1-1,5 \mathrm{~cm}$ compr., patente; lâmina concolor, 24-28 × 11-13 $\mathrm{cm}$, lustrosa, elíptica, base aguda, ápice agudo a cuspidado, margem inteira, ciliada; 5 nervuras, um par suprabasal, $1-1,5 \mathrm{~cm}$ da base, revestidas 
por tricomas estrigosos, proeminentes na face abaxial e impressas na face adaxial; com tricomas filiformes rígidos e adpressos, ramificados na base e tricomas estrelados na face abaxial. Flores e frutos não vistos.

Material examinado: Pitimbu, APA Tambaba, Andreza II, 16.IV.2010, C.M.L.R. Araújo 242 (JPB).

Henriettea sp. distingue-se das outras espécies de Melastomataceae estudadas por apresentar ramos e folhas com indumento estrigoso.

No Brasil, este gênero encontra-se amplamente distribuído em todas as regiões do país (Baumgratz 2012b). Na Paraíba, além da APA Tambaba, ele foi encontrado nos municípios de Bayeux, Mamanguape, Santa Rita e Sapé.

Na área de estudo, Henriettea sp. foi coletada em Mata de Tabuleiro, próximo a cursos d'água. Entretanto, não foi vista com flores ou frutos, o que impossibilitou a sua identificação e uma descrição mais completa.

\section{Miconia Ruiz \& Pavon}

Arbustos, ramos cilíndricos ou angulosos. Folhas elípticas, oblongas, obovadas, nervuras basais ou suprabasais, concolores ou discolores. Inflorescências racemosas, em panículas terminais com unidades escorpioides ou glomerulares. Brácteas e bractéolas agudas, persistentes. Flores 5-meras; hipanto globoso, glabro ou pubescente; cálice duplo; corola alva ou rosada, pétalas arredondadas, glabras; estames subisomóficos, filetes glabros, anteras subuladas, uniporadas, conectivo não prolongado; ovário, 4-carpelar, 4-locular, muitos óvulos por lóculo, placentação axilar; estilete alvo ou rosado, glabro. Baga imatura verde, madura atroviolácea ou verde-jade.

4.1. Miconia albicans (Sw.) Triana, Trans. Linn. Soc. London 28 (1): 116. 1871(1872). Fig. 3a-c

Arbustos, ca. 1,5 m alt.; ramos recobertos por indumento lanoso, não glanduloso. Folha com pecíolo 0,6-1,5 cm compr., patente; lâmina 6,5-14 $\times 3,5-6 \mathrm{~cm}$, discolor, lustrosa, elíptica, base obtusa, ápice agudo ou cuspidado, margem inteira; face abaxial com indumento lanoso e adaxial glabra; 5 nervuras basais. Inflorescências com unidades escorpioides, 6-14 × 5-8 cm. Brácteas e bractéolas ca. $1 \mathrm{~mm}$ compr. Flores 4-6 mm compr., sésseis; hipanto 1,8-2 × 1,5-2 mm, globoso, com indumento lanoso; tubo do cálice ca. $1 \mathrm{~mm}$ compr., lacínios externos inconspícuos, lacínios internos $0,8-1 \times$
1,3-1,5 mm compr., largamente triangulares, ápice obtuso; pétalas 2-2,9 × 1,8-2,5 mm, orbiculares, alvas, base truncada, ápice arredondado; estames subisomórficos, alvos; maiores com filete 3-3,2 mm compr., anteras 2,9-3 mm compr.; menores com filete 2,3-2,5 mm compr., anteras 2,1-2,5 mm compr.; ovário 4-locular, ca. 1,7 mm compr., globoso, glabro; estilete ca. 4,9 mm compr. Baga 4-6,9 × 6-8 mm, jovem creme, madura verde-jade.

Material examinado: Alhandra, Fazenda Itaperubu, 4.XI.1971, fl., R. Carvalheira (JPB 3084). Conde, APA Tambaba, 15.I.2010, fr., C.M.L.R. Araújo et al. 199 (JPB); Vale do Bucatu, 20.XI.2009, fr., C.M.L.R. Araújo et al. 197 (JPB). Pitimbu, APA Tambaba, Mucatu, 5.III.2010, fr., C.M.L.R. Araújo et al. 200 (JPB); Andreza II, 19.III.2010, fr., C.M.L.R. Araújo et al. 205 (JPB).

Material adicional: PARAÍBA: João Pessoa, Campus I da UFPB, 15.I.2010, fl. e fr., C.M.L.R. Araújo et al. 198 (JPB).

Miconia albicans é facilmente reconhecida pelas folhas discolores, lustrosas na face adaxial, inflorescências laxas e frutos verde-jade mesmo na maturação.

Ocorre por todo o território brasileiro (Goldenberg 2012). Na Paraíba, a espécie foi também encontrada em Areia, Bananeiras, João Pessoa, Mamanguape, Matinhas, Rio Tinto, Santa Rita e Sapé.

Em toda a APA de Tambaba, as populações apresentam muitos indivíduos, ocorrendo principalmente nas áreas mais abertas, mas no interior da mata os indivíduos de $M$. albicans foram encontrados formando populações pequenas, o que demonstra a tendência de a espécie ocorrer em locais ensolarados.

4.2. Miconia amoena Triana, Trans. Linn. Soc. London 28(1): 115. 1871 (1872). $\quad$ Fig. 3d-e

Arbustos, 1,5-1,8 m alt.; ramos com indumento lanoso, não glanduloso. Folha com pecíolo 1,2-2,4 cm compr., deflexa; lâmina 10-22,2 × 4,4-10 cm, discolor, opaca, obovada a elíptica, base obtusa, ápice obtuso ou agudo, margem inteira, levemente revoluta; face abaxial revestida por indumento lanoso, adaxial glabra; 3 nervuras basais. Inflorescências com unidades glomerulares 15-24 cm × 4-7 cm. Brácteas e bractéolas ca. $1 \mathrm{~mm}$ compr. Flores ca. $1 \mathrm{~cm}$ compr., sésseis; hipanto 2,5-3 × 1,5-2 mm, oblongo, recoberto por indumento lanoso; tubo do cálice ca. $1 \mathrm{~mm}$ compr., lacínios externos inconspícuos, lacínios internos $0,5-1 \times 1-1,5 \mathrm{~mm}$, largamente triangulares, ápice arredondado; pétalas 3-3,4 × 1,9-2,1 mm, oblongas, alvas, base truncada, ápice 

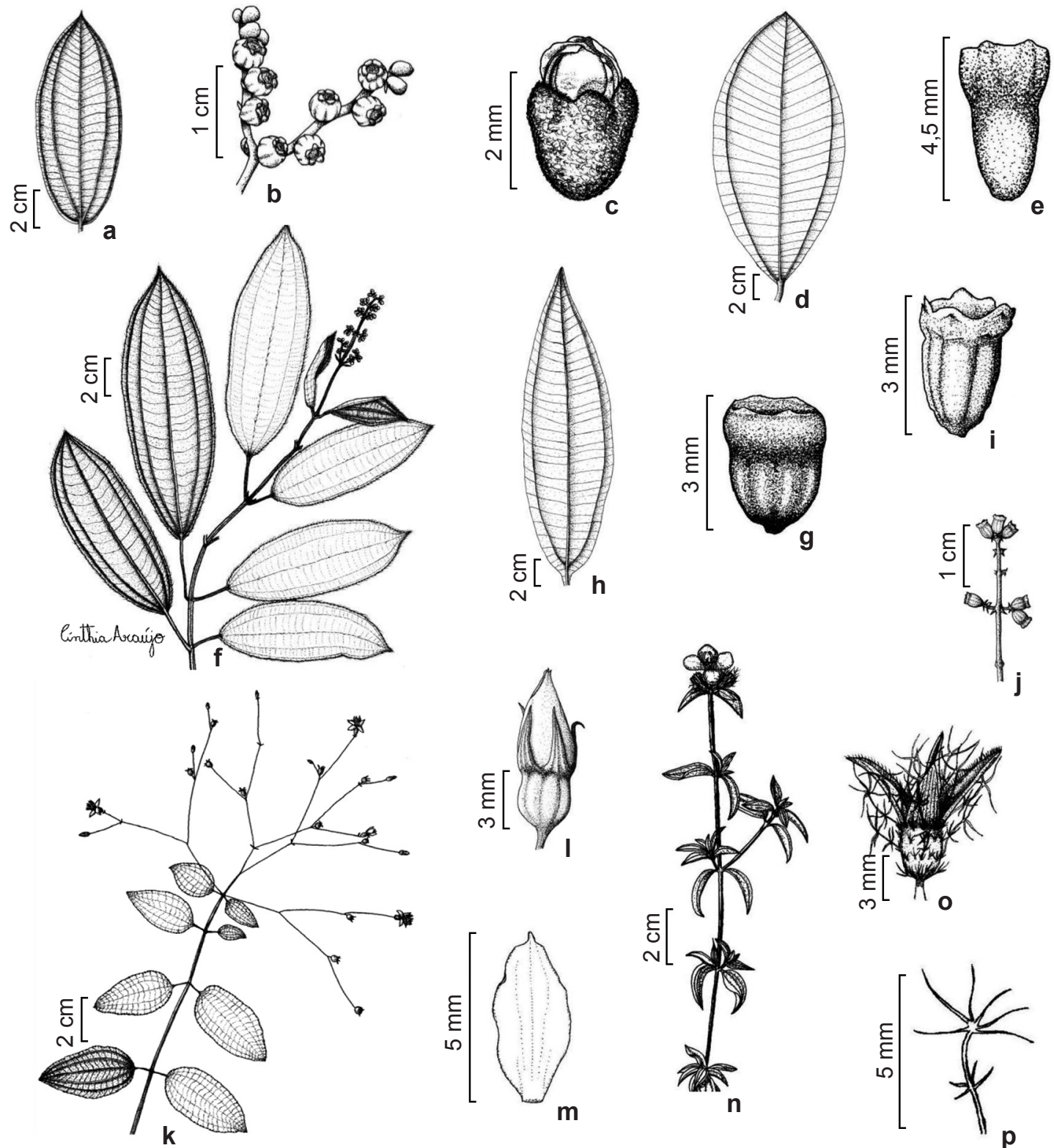

Figura 3 - a-c. Miconia albicans (Sw.) Triana. - a. folha, face abaxial; b. ramo com frutos; c. botão floral. d-e. M. amoena Triana. - d. folha, face abaxial; e. cálice. f-g. M. ciliata (Rich.) DC. - f. hábito; g. cálice. h-j. M. prasina (Sw.) DC. - h. folha, face abaxial; i. cálice. j. ramo com frutos. k-m. Nepsera aquatica Naudin. - k. hábito; 1. botão floral; m. pétala. n-p. Pterolepis glomerata (Rottb.) Miq. - n. hábito; o. cálice; p. tricoma do cálice. (a-b Araújo 197; c Araújo 198; d Araújo193; e Pessoa 574; f-g Araújo 201; h Araújo 202; i-j Barbosa 1497; k-m Araújo, 138; n-p Araújo 52).

Figure 3 - a-c. Miconia albicans (Sw.) Triana. - a. leaf, abaxial face; b. branch with fruits; c. floral bud. d-e. M. amoena Triana. - d. leaf, abaxial face; e. calyx. f-g. M. ciliata (Rich.) DC. - f. habit; g. calyx. h-j. M. prasina (Sw.) DC. - h. leaf, abaxial face; i. calyx. j. branch with fruits. k-m. Nepsera aquatica Naudin. - k. habit; 1. floral bud; m. petal. n-p. Pterolepis glomerata (Rottb.) Miq. - n. Habit; o. calyx; p. calyx trichome. (a-b Araújo 197; c Araújo 198; d Araújo193; e Pessoa 574; f-g Araújo 201; h Araújo 202; i-j Barbosa 1497; k-m Araújo, 138; n-p Araújo 52). 
arredondado; estames subisomórficos, cremes; maiores com filete 4,1-4,9 mm compr., anteras 2,8-3,1 mm compr.; menores com filete 4-4,5 mm compr., anteras 2,5-2,6 mm compr.; ovário ca. $2 \mathrm{~mm}$ compr., oblongo, glabro; estilete 7-8 $\mathrm{mm}$ compr. Baga 5-6 × 5,5-6,5 mm, jovem verde, madura atroviolácea.

Material examinado: Conde, APA Tambaba, Loteamento Enseada de Jacumã, 19.IX.2008, fr., C.M.L.R. Araújo et al. 94 (JPB); APA Tambaba, 26.IX.2008, fl., I.B. Lima et al. 1014 (JPB); Fazenda Malhada de Baixo, 26.IX.2008, fl., C.M.L.R. Araújo et al. 101 (JPB); Fazenda Frei Anastácio, 24.XI.2008, fl., M.F.M. Brito \& C. Santiago 28 (JPB); Vale do Bucatu, 6.XI.2009, fl., C.M.L.R. Araújo et al. 193 (JPB); Vale do Bucatu, 20.XI.2009, fl., C.M.L.R. Araújo et al. 196 (JPB); Mata da Chica, 21.V.2010, fl., C.M.L.R. Araújo et al. 209 (JPB).

Material adicional: PARAÍBA: Mamanguape, Estação Ecológica de Mamanguape, Cabeça de Boi, 24.III.2010, fl., M.C. Pessoa et al. 574 (JPB).

Miconia amoena assim como $M$. albicans, apresenta folhas discolores, mas distingue-se pela lâmina foliar distintamente maior e opaca, com 3 nervuras basais e anteras cremes.

A espécie ocorre nas Regiões Nordeste e Sudeste (Goldenberg 2012). Na Paraíba, foi encontrada em Matas de Tabuleiro e nos Tabuleiros da APA Tambaba.

4.3. Miconia ciliata (Rich.) DC., Prodr. 3: 179-180. 1828.

Fig. $3 \mathrm{f}-\mathrm{g}$

Arbustos, ca. 1,5 m alt.; ramos glabros; nós dos ramos mais jovens com tricomas filiformes. Folha com pecíolo 0,7-3 cm compr., canaliculado com tricomas filiformes na região sulcada, deflexa; lâmina 5-14,5 × 2,4-5 cm, concolor, lustrosa, elíptica a oblonga, base arredondada a cuneada, ápice agudo a cuspidado, margem serreada, ciliada; face abaxial geralmente glabra podendo apresentar tricomas esparsos, filiformes, face adaxial glabra; 5 nervuras basais. Inflorescências com unidades escorpioides 7,6-14 × 2,7-6 cm. Brácteas e bractéolas ca. $1 \mathrm{~mm}$ compr. Flores 4-5 mm compr., sésseis; hipanto ca. $2 \times 2 \mathrm{~mm}$, globoso, glabro; tubo do cálice ca. $1 \mathrm{~mm}$ compr., lacínios externos inconspícuos, lacínios internos ca. 0,5 × 1,5 mm, largamente deltoides, ápice obtuso; pétalas 2-2,3 $\times$ 1,9-2,1 mm, róseas ou lilases, base truncada, ápice arredondado; estames subisomórficos, róseos ou lilases; maiores com filete 2-2,3 mm compr., anteras 1,5-1,7 mm compr.; menores com filete 1,7-2 mm compr., anteras 1-1,2 mm compr.; ovário ca. 1,5 mm compr., globoso, glabro; estilete ca. $3 \mathrm{~mm}$ compr. Baga 4-6 × 4,5-6 mm, jovem verde, madura atroviolácea.

Material examinado: Conde, APA Tambaba, Fazenda Malhada de Baixo, 26.IX.2008, fl., C.M.L.R. Araújo et al. 96 (JPB); Vale do Bucatu, 6.XI.2009, fl. e fr., C.M.L.R. Araújo et al. 191 (JPB); 20.XI.2009, fl. e fr., C.M.L.R. Araújo et al. 195 (JPB); Mata da Chica, 28.V.2010, fl. e fr., C.M.L.R. Araújo et al. 213 (JPB); APA Tambaba, 7.XI.2008, fr., P.C. Gadelha Neto et al. 2499 (JPB). Pitimbu, APA Tambaba, Mucatu, 5.III.2010, fl. e fr., C.M.L.R. Araújo et al. 201 (JPB); APA Tambaba, Andreza II, 19.III.2010, fr., C.M.L.R. Araújo et al. 204 (JPB); 16.IV.2010, fr., C.M.L.R. Araújo et al. 208 (JPB).

Miconia ciliata é facilmente reconhecida pelos ramos cilíndricos com nós bem definidos, pelas folhas lustrosas com margem ciliada e pecíolo conspicuamente canaliculado, flores pequenas, róseas ou lilases, caracteres que auxiliam na sua identificação. Variações marcantes foram observadas nas folhas dos indivíduos de $M$. ciliata, quanto ao tamanho e a consistência, de acordo com o ambiente em que estavam estabelecidos.

A espécie ocorre nas Regiões Norte, Nordeste, Centro-Oeste e Sudeste do país (Goldenberg 2012). Na Paraíba, M. ciliata foi encontrada em Bayeux, João Pessoa, Rio Tinto e Santa Rita. Na APA Tambaba, ocorre no interior das Matas de Tabuleiro e em áreas abertas.

4.4. Miconia prasina (Sw.) DC., Prodr. 3: 188. 1828.

Fig. $3 h-j$

Arbustos, 3,5-4 m alt.; ramos com tricomas estrelados e estrelado-estipitados, não glandulosos. Folha com pecíolo 1-2,5 cm compr., alado, deflexa; lâmina 17-24,5 × 6,2-8,5 cm, concolor, lustrosa, oblonga, base decurrente, ápice agudo, margem inteira, levemente revoluta; ambas as faces glabras; 3 nervuras, com um par suprabasal à $0,5-1 \mathrm{~cm}$ da base. Inflorescências com unidades dicasiais, 6,5-7 $\times 11-12 \mathrm{~cm}$. Brácteas e bractéolas ca. $1 \mathrm{~mm}$ compr. Flores 4-5 mm compr. sésseis; hipanto ca. $2 \times 1,5$ $\mathrm{mm}$, oblongo, piloso no ápice; tubo do cálice ca. $0,5 \mathrm{~mm}$ compr., lacínios externos inconspícuos, lacínios internos ca. $0,5 \times 1,5 \mathrm{~mm}$ compr., largamente deltoides, ápice obtuso a arredondado; pétalas $2-2,5 \times 1-1,2 \mathrm{~mm}$, alvas, base truncada, ápice arredondado; estames subisomórficos, alvos; maiores com filete 4-4,2 mm compr., anteras 2,8-3 mm compr.; menores com filete 3-3,2 mm compr., anteras 2,2-2,5 mm compr.; ovário ca. 1,5 mm compr., globoso, piloso no ápice; estilete ca. 5,5 mm compr. Baga 5-6×6,5-7,5 mm, jovem verde, madura atroviolácea. 
Material examinado: Pitimbu, APA Tambaba, Mucatu, 5.III.2010, fr., C.M.L.R. Araújo et al. 202 (JPB).

Material adicional: PARAÍBA: Areia, Mata de encosta próxima ao Campus da UFPB, III.1996, fl., M.R. Barbosa 1497 (JPB).

Miconia prasina distingue-se das demais espécies do gênero pela lâmina foliar completamente glabra com um par de nervuras suprabasais e pecíolo alado.

No Brasil, a espécie ocorre em todas as regiões do país (Goldenberg 2012). Mas, na Paraíba, só foi registrada em Pitimbu e em Areia. Na área estudada a espécie foi encontrada ocorrendo na Mata de Tabuleiro, sendo a única do gênero que não foi encontrada em áreas abertas ou antropizadas.

\section{Nepsera Naudin}

5.1. Nepsera aquatica (Aubl.) Naudin, Ann. Sci. Nat., Bot. sér. 3, 13: 28. 1850.

Fig. 3k-m

Subarbustos, 0,5-1 m alt.; ramos com tricomas filiformes, não glandulosos, esparsos. Folha com pecíolo 0,5-1,5 cm compr., delgado, com tricomas filiformes, ca. $1 \mathrm{~mm}$ compr., deflexa; lâmina 2,5-7,5 × 1,3-4 cm, lustrosa, oval a elíptica com pontuações esbranquiçadas, base obtusa a truncada, ápice agudo, margem serreada; ambas as faces glabras; 5 nervuras basais, raramente 7 . Inflorescências dicasiais, axilares ou terminais com unidades de inflorescências dicasiais, 13-28 $\times 7-22 \mathrm{~cm}$. Brácteas e bractéolas ca. $1 \mathrm{~mm}$ compr., filiformes, caducas. Flores ca. $8 \mathrm{~mm}$ compr.; pedicelo ca. $3 \mathrm{~mm}$ compr.; hipanto ca. 1,7 mm compr., globoso, glabro; tubo do cálice ca. 0,6 mm, compr., lacínios ca. 1,7 mm compr., agudos; pétalas 4,9-5,1 × 2-2,4 mm, estreitamente elípticas, base aguda, ápice agudo, alvas; estames subisomórficos; maiores com filete 2,9-3 mm compr., alvo, anteras ca. 2,3-2,5 mm compr., lilases, conectivo curto 0,3-0,5 mm compr., apêndice ventral ca. 0,5 mm compr., bilobado; menores com filete 2,2-2,5 mm compr., alvo, anteras 1,9-2,1 mm compr., lilases, conectivo curto $0,3-0,5 \mathrm{~mm}$ compr., apêndice ventral ca. 0,5 mm compr., bilobado; ovário 4-locular, livre, ca. 1,5 mm compr., globoso, glabro; estilete 5-5,1 mm compr. Cápsula loculicida ca. 1,5 $\times 1,5 \mathrm{~mm}$, jovem verde, madura creme.

Material examinado: Conde, APA Tambaba, Fazenda Malhada do Alto, 17.X.2008, fl. e fr., C.M.L.R. Araújo et al. 138 (JPB); APA Tambaba, 26.IX.2008, fl. e fr., I.B. Lima et al. 1013 (JPB).

Nepsera aquatica apresenta como caracteres diagnósticos os ramos avermelhados, folhas com pontuações esbranquiçadas e inflorescências com raque longa, delgada e bastante frágil.

Ocorre nas Regiões Norte e Nordeste do Brasil (Baumgratz 2012c). Na Paraíba, esta espécie também foi encontrada em João Pessoa e Mamanguape. Na APA Tambaba, geralmente habita o interior da mata, principalmente em locais bastante sombreados, úmidos ou completamente encharcados.

\section{Pterolepis (DC.) Miq.}

6.1. Pterolepis glomerata (Rottb.) Miq., Comm. Phytogr. 2: 78. 1840.

Fig. 3n-p

Ervas 20-40 cm alt.; ramos com tricomas filiformes, não glandulosos. Folha com pecíolo 1-1,6 mm compr., delgado, deflexa; lâmina 1,4-2 $\times 0,5-0,9 \mathrm{~cm}$, opaca, oblonga, estreito-lanceolada a largamente-lanceolada, base aguda, ápice agudo, margem crenada, ciliada; ambas as faces revestidas por indumento seríceo; 3 nervuras basais. Inflorescências dicasiais, axilares ou terminais, 1,3-2 × 2-2,5 cm. Brácteas e bractéolas 7-8 $\times 2-3 \mathrm{~mm}$, lanceoladas, persistentes. Flores ca. $1 \mathrm{~cm}$ compr.; pedicelo ca. $2 \mathrm{~mm}$ compr.; hipanto ca. $3 \times 3 \mathrm{~mm}$, globoso, revestido por tricomas 2-6,5 mm compr., ramificados, não glandulosos; tubo do cálice ca. $1 \mathrm{~mm}$ compr., lacínios ca. 3 mm compr., deltoides; pétalas $1-1,2 \times 0,7-1 \mathrm{~cm}$, obovadas, margeadas por glândulas, base aguda, ápice arredondado, róseas; estames subisomórficos; maiores com filete 4,5-5 mm compr., creme, anteras ca. 3-3,1 mm compr., amarelas com metade distal lilás, conectivo não prolongado, apêndice ventral ca. 0,5 mm compr., bituberculado, amarelo; menores com filete ca. 3,8-4 mm compr., creme, anteras 2,6-2,9 mm compr., amarelas com metade distal lilás, conectivo não prolongado, apêndice ventral ca. 0,5 mm compr., bituberculado, amarelo; ovário 4-locular, livre, ca. $3 \mathrm{~mm}$ compr., globoso, com tricomas filiformes no ápice, 1-1,3 mm compr.; estilete ca. $8 \mathrm{~mm}$ compr. Cápsula loculicida 3-4 × 2-4 mm, jovem verde, madura castanha.

Material examinado: Conde, APA Tambaba, Loteamento Barra de Jacumã, 25.VII.2008, fl., C.M.L.R. Araújo \& Gisele Freitas 52 (JPB); Vale do Bucatu, 6.XI.2009, fl. e fr., C.M.L.R. Araújo et al. 190 (JPB); Vale do Bucatu, 20.XI.2009, fl. e fr., C.M.L.R. Araújo et al. 194 (JPB). Pitimbu, APA Tambaba, Bacia do Mucatu, 25.IX.2009, fl. e fr., C.M.L.R. Araújo et al. 188 (JPB).

Pterolepis glomerata apresenta caracteres que permitem o seu fácil reconhecimento, como tricomas vermelhos, longos e ramificados no hipanto, assim como os lacínios do cálice avermelhados. 
A espécie ocorre em todas as regiões do Brasil (Romero 2012). Este é o primeiro registro do gênero para a Paraíba. Além da área de estudo, também foi encontrada no Litoral Norte, em Rio Tinto. Na APA Tambaba as populações são numerosas, principalmente em áreas abertas, com solo geralmente arenoso ou areno-argiloso, próximo aos cursos d'água.

\section{Agradecimentos}

As autoras agradecem aos Curadores dos Herbários consultados, ao Dr. William Wayt Thomas a colaboração e sugestões e a Carlos Antônio Gomes Santiago, Ariclenes de Almeida Melo Araújo e Michele Fernanda Marques de Brito, o apoio nas atividades de campo.

\section{Referências}

Amorim, A.M.; Goldenberg, R. \& Michelangeli, F.A. 2009. Anew species of Physeterostemon (Melastomataceae) from Bahia, Brazil, with notes on the phylogeny of the genus. Systematic Botany 34: 324-329.

Araújo, J.A.G. 2001. A família Melastomataceae Juss. em um fragmento de floresta atlântica, município de Paulista, estado de Pernambuco, Brasil. Dissertação de Mestrado. Universidade Federal Rural de Pernambuco, Recife. 45p.

Barberena, F.F.V.A.; Baumgratz, J.F.A. \& Chiavegatto, B. 2008. Melastomataceae no Parque Nacional do Itatiaia, Sudeste do Brasil: tribos Bertolonieae e Merianieae. Rodriguésia 59: 381-392.

Barberena, F.F.V.A.; Chiavegatto, B. \& Baumgratz, J.F.A. 2010. Melastomataceae nos remanescentes florestais do Parque Estadual do Ibitipoca, Minas Gerais, Brasil. Boletim de Botânica da Universidade de São Paulo 28: 141-157.

Barbosa, M.R.V.; Agra, M.F.; Sampaio, E.V.S.B.; Cunha, J.P. \& Andrade, L.A. 2004. Diversidade Florística na Mata do Pau-Ferro, Areia, Paraíba. In: Porto, K. C.; Cabral, J. J. P. \& Tabarelli, M. (eds.). Brejos de altitude em Pernambuco e Paraíba: história natural, ecologia e conservação. Ministério do Meio Ambiente, Brasília. Pp. 111-122.

Barbosa, M.R.V. \& Thomas, W.W. 2002. Biodiversidade, conservação e uso sustentável da Mata Atlântica no Nordeste. In: Araújo, E.L.; Moura, A.N.; Sampaio, E.V.S.B.; Gestinari, L.M.S.; Carneiro, J.M.T. (eds.). Biodiversidade, conservação e uso sustentável da flora do Brasil. UFRPE, Recife. Pp. 19-22.

Barbosa, M.R.V.; Thomas, W.W.; Zárate, E.L.P.; Lima, R.B.; Agra, M.F.; Lima, I.B.; Pessoa, M.C.R.; Lourenço, A.R.L.; Delgado-Júnior, G.C.; Pontes, R.A.S.; Chagas, E.C.O.; Viana, J.L.; GadelhaNeto, P.C.; Araújo, C.M.L.R.; Araújo, A.A.M.; Freitas, G.B.; Lima, J.R.; Silva, F.O.; Vieira, L.A.F.;
Pereira, L.A.; Costa, M.R.T.; Duré, R.C. \& Sá, M.G.V. 2011. Checklist of the vascular plants of the Guaribas Biological Reserve, Paraíba, Brazil. Revista Nordestina de Biologia 20: 79-106.

Baumgratz, J.F.A. 2012a. Comolia. In: Forzza, R.C. et al. (eds.). Lista de espécies da flora do Brasil. Jardim Botânico do Rio de Janeiro. Disponível em $<$ http:// floradobrasil.jbrj.gov.br/2012/FB085242>. Acesso em 7 Mai 2012.

Baumgratz, J.F.A. 2012b. Henriettea. In: Forzza, R.C. et al. (eds.). Lista de espécies da flora do Brasil. Jardim Botânico do Rio de Janeiro. Disponível em $<$ http://floradobrasil.jbrj.gov.br/2012/FB009472>. Acesso em 7 maio 2012.

Baumgratz, J.F.A. 2012c. Nepsera. In: Forzza, R.C. et al. (eds.). Lista de espécies da flora do Brasil. Jardim Botânico do Rio de Janeiro. Disponível em $<$ http:// floradobrasil.jbrj.gov.br/2012/FB009827>. Acesso em 7 Mai 2012.

Baumgratz, J.F.A.; Amorim, A.M. \& Jardim, A.B. 2011. Two new species of Bertolonia (Melastomataceae) from the Brazilian Atlantic Forest. Kew Bulletin 66: 273-279.

Baumgratz, J.F.A.; Bernardo, K.F.R.; Chiavegatto, B.; Goldenberg, R.; Guimarães, P.J.F.; Kriebel, R.; Martins, A.B.; Michelangeli, F.A.; Reginato, M.; Romero, R.; Souza, M.L.D.R. \& Woodgyer, E. 2012. Melastomataceae. In: In: Forzza, R.C. et al. (eds.). Lista de espécies da flora do Brasil. Jardim Botânico do Rio de Janeiro. Disponível em $<$ http:// floradobrasil.jbrj.gov.br/2012/FB000161>. Acesso em 4 Mai 2012.

Baumgratz, J.F.A. \& Chiavegatto, B. 2006. Nova espécie de Miconia Ruiz \& Pav. (Melastomataceae) para Minas Gerais, Brasil. Acta Botanica Brasilica 20: 483-486.

Baumgratz, J.F.A. \& Souza, M.L.D.R. 2005. Duas novas espécies de Leandra Raddi (Melastomataceae) para o estado de São Paulo, Brasil. Acta Botanica Brasilica 19: 573-578.

Baumgratz, J.F.A.; Souza, M.L.D.R.; Carraça, D.C. \& Abbas, B.A. 2006. Melastomataceae na Reserva Biológica de Poço das Antas, Silva Jardim, Rio de Janeiro, Brasil: aspectos florísticos e taxonômicos. Rodriguésia 57: 591-646.

Baumgratz, J.F.A.; Souza, M.L.D.R. \& Tavares, R.A.M. 2007. Melastomataceae na Reserva Ecológica de Macaé de Cima, Nova Friburgo, Rio de Janeiro, Brasil: I-Tribos Bertolonieae, Merianieae e Microlicieae. Rodriguésia 58: 797-822.

Camargo, E.A. \& Goldenberg, R. 2007. Leandra seção Leandraria (Melastomataceae) no estado do Paraná, Brasil. Iheringia, Série Botânica 62: 103-111.

Camargo, E.A.; Souza, C.M.F.; Caddah, M.K. \& Goldenberg, R. 2009. O gênero Leandra, seções Carassanae, Chaetodon, Niangae, Oxymeris e Secundiflorae (Melastomataceae) no estado do Paraná. Rodriguésia 60: 595-631. 
Chagas, E.C.O. 2012. O gênero Miconia Ruiz \& Pav. (Melastomataceae) na Floresta Atlântica do Nordeste Oriental. Dissertação de Mestrado. Universidade Federal de Pernambuco, Recife. 159p.

Clausing, G. \& Renner, S.S. 2001. Molecular phylogenetics of Melastomataceae and Memecylaceae: implications for character evolution. American Journal of Botany 88: 486-498.

Cogniaux, A. 1891. Melastomataceae. In: De Candolle, A.L.P.P. \& De Candolle, A.C.P. (eds.). Monographiae phanerogamarum. Vol. 7. G. Masson, Paris. Pp. 1-1256.

Conceição, G.M.; Ruggieri, A.C. \& Magalhães, E.R. 2010. Melastomataceae da Área de Proteção Ambiental Municipal do Inhamum, Caxias, Maranhão. Revista de Biologia e Farmácia 4: 83-88.

De Candolle, A.P. 1828. Prodomus systematis naturalis regni vegetabilis. Vol. 3, pars 3. Treuttel et Würtz, Paris. Pp. 99-494.

Freitas, J.G.; Santos, A.K.A. \& Oliveira, R.P. 2012. Tibouchina bracteolata and T. comosa (Melastomataceae, Melastomeae): two new species to the Chapada Diamantina, Bahia, Brazil. Systematic Botany 37: 189-196.

Goldenberg, R. 2004. O gênero Miconia (Melastomataceae) no estado do Paraná, Brasil. Acta Botanica Brasilica 18: 927-947.

Goldenberg, R. 2012. Miconia. In: Forzza, R.C. et al. (eds.). Lista de espécies da flora do Brasil. Jardim Botânico do Rio de Janeiro. Disponível em $<$ http:// floradobrasil.jbrj.gov.br/2012/FB009666>. Acesso em 7 Mai 2012.

Goldenberg, R.; Baumgratz, J.F.A. \& Souza, M.L.D.R. 2012. Taxonomia de Melastomataceae no Brasil: retrospectiva, perspectivas e chave de identificação para os gêneros. Rodriguésia 63: 145-161.

Goldenberg, R.; Souza, C.M.F. \& Dequech, H.B. 2005. Clidemia, Ossaea e Pleiochiton (Melastomataceae) no estado do Paraná, Brasil. Hoehnea 32: 453-466.

Jardim, A.Q.B.S. 2010. Melastomataceae Juss. de floresta montana no complexo Serra das Lontras, Bahia, Brasil. Dissertação de Mestrado. Universidade Estadual de Feira de Santana, Feira de Santana. 91p.

Jussieu, A.L. 1789. Melastomae. In: Jussieu, A.L. (ed.). Genera Plantarum. Stanford University Library, Stanford. Pp. 328-330.

Kinoshita, L.S.; Martins, A.B. \& Bernardo, K.F.R. 2007. As Melastomataceae do município de Poços de Caldas, Minas Gerais, Brasil. Hoehnea 34: 447480, 7 fig.

Krasser, F. 1893. Melastomataceae. In: Engler, A. \& Prantl, K. (eds.). Die natürlichen Pflanzenfamilien. Vol. 3, p. 7. Engelman, Leipzig. Pp. 130-199.

Lima, F.G.C.; Seixas, E.N.C. \& Silva, M.A.P. 2007. Melastomataceae no Cariri Cearense, nas cidades de Barbalha, Crato, Jardim e Santana do Cariri, Ceará, Brasil. Revista Brasileira de Biociências 5: 39-41.
Martins, A.B. 2000. Three new Brazilian species in the genus Marcetia (Melastomataceae, Melastomeae). Novon 10: 224-229.

Meyer, F.S.; Guimarães, P.J.F. \& Kozera, C. 2010. Uma nova espécie de Tibouchina Aubl. (Melastomataceae), endêmica do Paraná, Brasil. Revista Brasileira de Botânica 33: 265-269.

Michelangeli, F.A. \& Reginato, M. 2012. Clidemia. In: Forzza, R.C. et al. (eds.). Lista de espécies da flora do Brasil. Jardim Botânico do Rio de Janeiro. Disponível em $<$ http://floradobrasil.jbrj. gov.br/2012/FB009444>. Acesso em 7 Mai 2012.

Oliveira, F.X.; Andrade, L.A. \& Félix, L.P. 2006. Comparações florísticas e estruturais entre comunidades de Floresta Ombrófila Aberta com diferentes idades, no Município de Areia, PB, Brasil. Acta Botanica Brasilica 20: 861-873.

Oliveira-Filho, A.T. \& Carvalho, D.A. 1993. Florística e fisionomiada vegetação no extremo norte do litoral da Paraíba. Revista Brasileira de Botânica 16: 115-130.

Pedrosa, E.C.T. 2006. Caracterização do uso e ocupação da terra em relação à morfologia do relevo na área de Proteção Ambiental Tambaba, Paraíba. Monografia de Graduação. Universidade Federal da Paraíba, João Pessoa. 92p.

Pereira, M.S. \& Alves, R.R.N. 2006. Composição florística de um remanescente de Mata Atlântica na Área de Proteção Ambiental Barra do Rio Mamanguape, Paraíba, Brasil. Revista de Biologia e Ciências da Terra 6: 357-366.

Pessoa, L.M.; Pinheiro, T.S.; Alves, M.C.J.L.; Pimentel, R.M.M. \& Zickel, C.S. 2009. Flora lenhosa em um fragmento urbano de floresta atlântica em Pernambuco. Revista de Geografia 26: 247-262.

Renner, S.S. 1993. Phylogeny and classification of the Melastomataceae and Memecylaceae. Nordic Journal of Botany 13: 519-540.

Renner, S.S. \& Goldenberg, R. 2011. A new name and a new synonym in Miconia (Melastomataceae). Phyto Keys 3: 35-37.

Renner, S.S.; Triebel, D.; Almeda, F.; Stone, D.; Ulloa, C.U.; Michelangeli, F.A.; Goldenberg, R. \& Cifuentes, H.M. Melastomataceae.Net. 2010. A site with information on the biodiversity of Melastomataceae. Disponível em $<$ www. melastomataceae.net $>$. Acesso em 25 Jun 2010.

Rodal, M.J.N. \& Nascimento, L.M. 2002. Levantamento florístico da floresta serrana da Reserva Biológica de Serra Negra, microrregião de Itaparica, Pernambuco, Brasil. Acta Botanica Brasilica 16: 481-500.

Romero, R. 2012. Pterolepis. In: Forzza, R.C. et al. (eds.). Lista de espécies da flora do Brasil. Jardim Botânico do Rio de Janeiro. Disponível em $<$ http://floradobrasil. jbrj.gov.br/2012/FB009857>. Acesso em 7 Mai 2012.

Romero, R. \& Martins, A.B. 2002. Melastomataceae do Parque Nacional da Serra da Canastra, Minas 
Gerais, Brasil. Revista Brasileira de Botânica 25: 19-24.

Santos, A.K.A. 2005. A família Melastomataceae: tribo Melastomeae Bartl., no município de Rio de Contas, Bahia, Brasil. Dissertação de Mestrado. Universidade Estadual de Feira de Santana, Feira de Santana. 142p.

Santos, A.K.A. 2009. Estudos filogenéticos e biossistemáticos no gênero Marcetia DC. (Melastomataceae). Tese de Doutorado. Universidade Estadual de Feira de Santana, Feira de Santana. 156p.

Santos, A.K.A.; Martins, A.B.; Silva, T.R.S. 2008. Marcetia candolleana (Melastomeae Melastomataceae), a new species from Bahia (Brasil). Kew Bulletin 63: 315-318.

Santos, A.K.A. \& Silva, T.R.S. 2005. A família Melastomataceae no município de Rio de Contas, Bahia, Brasil. Sitientibus Série Ciências Biológicas 5: 76-92.

Seco, R.C. 2006. Estudos taxonômicos no gênero Comolia DC. (Melastomataceae - Melastomeae) no Brasil. Dissertação de Mestrado. Universidade Estadual de Campinas, São Paulo. 113p.

Silva, M.A.O. \& Romero, R. 2008. Melastomataceae das serras do município de Delfinópolis, Minas Gerais, Brasil. Rodriguésia 59: 609-647.

Sobrinho, J.G.C. \& Queiroz, L.P. 2005. Composição florística de um fragmento de Mata Atlântica na Serra da Jibóia, Santa Terezinha, Bahia, Brasil. Sitientibus Série Ciências Biológicas 5: 20-28.

SUDEMA. 2012. Área de Proteção Ambiental (APA) de Tambaba. Disponível em $<$ http://www.sudema. pb.gov.br/index.php?view $=$ category $\&$ catid $=5 \&$ op tion=com_joomgallery $>$. Acesso em 9 Mai 2012.

Souza, A.C.R.; Almeida Jr., E.B. \& Zickel, C.S. 2009. Riqueza de espécies de sub-bosque em um fragmento florestal urbano, Pernambuco, Brasil. Biotemas 22: 57-66.

Triana, J. 1871. Les Melastomacées. Transaction Linnean Society of London, Botany 28: 1-188.

Vliet, G.J.C.M.; Koek-Noorman, J. \& Ter Welle, B.J.H. 1981. Wood anatomy, classification and phylogeny of the Melastomataceae. Blumea 27: 463-473. 